\title{
Enablers and challenges when engaging local communities for urban biodiversity conservation in Australian cities
}

\author{
Lucy Taylor $^{1}$ (D) Cecily J. Maller ${ }^{2} \cdot$ Kylie Soanes $^{1} \cdot$ Cristina E. Ramalho $^{3} \cdot$ Abhilasha Aiyer $^{4} \cdot$ Kirsten M. Parris $^{1}$. \\ Caragh G. Threlfall,
}

Received: 9 August 2020 / Accepted: 19 July 2021 / Published online: 14 August 2021

(c) The Author(s) 2021

\begin{abstract}
Across all landscape types, environmental managers work with communities to conserve biodiversity. The effectiveness of conservation practice, however, relies on acknowledging differences in preferences and values of nature. Implementing urban conservation is challenging because cities have diverse social, cultural and ecological attributes, meaning there are no simple solutions for the management or co-management of biodiversity. There is little guidance for urban environmental managers on how to 1) engage local urban communities and 2), implement conservation actions specific to cities and their communities. We conducted semi-structured interviews with 27 environmental managers from government and not-for-profit organizations across five Australian capital cities to 1) explore how environmental managers engaged local communities, and 2) understand the factors that enabled or constrained that engagement in conservation. Our aim was to understand the enablers and constraints of engagement with a view to share insights and patterns in the context of the Intergovernmental Platform on Biodiversity and Ecosystem Services (IPBES) conceptual framework's recognition of the diversity of values associated with nature's contributions to people (NCP). We found that urban environmental managers facilitated NCP by working to improve people's relationship with nature. Interviewees reported a range of enablers for community-based biodiversity conservation, including supportive organizational policies and strategies, community support, engaging Indigenous advisory groups, and deploying multi-use, integrative human-nature designs. Constraints and challenges included a lack of top-down commitment, reliance on individuals, and overly simplistic engagement strategies. Based on these findings, we identified opportunities for improved community engagement relevant to organizations responsible for urban environmental management.
\end{abstract}

Keywords Socio-ecological system · Qualitative method · Nature's contribution to people · Relational values · Urban ecology $\cdot$ Urban nature

Handled by Shizuka Hashimoto, University of Tokyo, Japan.

Lucy Taylor

whoneedsnature@gmail.com; taylor.11@unimelb.edu.au

1 School of Ecosystem and Forest Sciences, The University of Melbourne, Baldwin Spencer Building (113), Parkville, VIC 3010, Australia

2 Centre for Urban Research, School of Global, Urban and Social Studies, RMIT University, 124 La Trobe Street, Melbourne, VIC 3000, Australia

3 School of Biological Sciences, The University of Western Australia, M090 35 Stirling Highway, Perth, WA 6009, Australia

4 School of Life and Environmental Sciences, The University of Sydney, A08, Sydney, NSW 2006, Australia

\section{Introduction}

Often equipped with ecological and other scientific knowledge, environmental managers are responsible for important conservation and restoration work across a range of ecosystems (Ives \& Kendal, 2014). Cities are often located in biodiversity hotspots and have great potential for species conservation (Ives et al., 2016; Shaffer, 2018; Soanes \& Lentini, 2019). To conserve urban biodiversity, environmental managers have historically sought to reduce the impact of humans on the natural world (Ives \& Kendal, 2014). However, those historical approaches to conservation are not always viable, particularly in cities, where conservation actions need a degree of social license to proceed and 
succeed (see Kendal \& Ford, 2018 for a discussion about conservation and social licence).

Despite being nature-focused, conservation and restoration actions are contingent on human decision-making, often in value-laden social contexts (Backstrom et al., 2018). Cities are the perfect example of socio-ecological systems, where environmental management actions require both scientific and social considerations as part of more-thanhuman worlds (Maller, 2018; Whatmore, 2006). It is critical for urban environmental managers to incorporate understandings from the social sciences in their roles, such as an appreciation of how to engage the public, how to understand social systems and changes, and how to incorporate values in decision-making and conflict mitigation (Endter-Wada et al., 1998; Ives \& Kendal, 2014).

People's responses to the processes and results of conservation actions are influenced by their values. While in an abstract sense, people may consider that protecting nature is important for humans (instrumental values) or for nature itself (intrinsic values), it is their everyday relationships with nature and the associated range of preferences, principles and virtues assigned to those relationships that is often at the centre of human responses to conservation efforts (Chan et al., 2016). These more material, consequential and reciprocal relationships people have with nature are conceptualized as 'relational values' (Chan et al., 2016).

The Intergovernmental Platform on Biodiversity and Ecosystem Services (IPBES) developed its conceptual framework to support its objective of assessing and improving sustainable development, biodiversity and ecosystem function (Díaz et al., 2015). As part of the framework, relational values represent a pluralistic, inclusive understanding of values (Chan et al., 2018). Where conservation actions result in conflicts between different groups or human actors, such as environmental managers and residents, this often stems from differences between people based on their relational values, not between people and nature per se (Chan et al., 2016; Redpath et al., 2015). For example, a resident may be a member of a community-based group that aims to encourage native bees using appropriate plant palettes in residential gardens. However, the result of that conservation work may produce a conflict with a neighbor who perceives the higher abundance of bees as a health risk or a threat to wellbeing. To ensure the maximum effectiveness of conservation actions, urban environmental management must actively engage communities to understand people's needs, preferences and relational values (Martin et al., 2016b), and to collaborate, co-produce or co-manage urban nature. We use the term 'nature' to encompass all facets of the natural world, including biodiversity, ecosystems and ecosystem function (Díaz et al., 2015).

The International Union for the Conservation of Nature (IUCN) defines collaborative management, or co-management, as "a partnership in which government agencies, local communities and resource users, non-governmental organizations and other stakeholders negotiate, as appropriate to each context" (IUCN, 1996, Sect. 1.42) the management of a place or resource. The range of possible collaborative management models represents a continuum of governance (Carlsson \& Berkes, 2005), partly due to the diversity of cultures and people with different needs and values that a 'community' can include (Barraket, 2004; Buijs et al., 2016). In cities, engaging with a range of understandings and expectations creates additional complexity for urban environmental managers (Backstrom et al., 2018; Buijs et al., 2016; Pascual et al., 2017). For example, managing the access for people in natural spaces involves a range of considerations that could impact both biodiversity and communities' expectations of recreation or daily life. Active contributions by urban citizens are possible with appropriate management (Buijs et al., 2016). Working within diverse human communities in cities, means that there is no single solution or way for environmental managers to engage communities (Armitage et al., 2012). However, improved biodiversity conservation practice, especially in urban centres, may only be realized if the full spectrum of ecological, social and cultural values are acknowledged and harnessed to co-produce knowledge about best practice ecosystem management (Pascual et al., 2021).

A key part of the IPBES conceptual framework is the notion of 'nature's contribution to people' (NCP), that is intended to be a conduit between nature's needs and the achievement of a good quality of life for people (Pascual et al., 2017). The framework recognizes the variety of social perspectives, noting that engagement should be inclusive enough to integrate the often western-science background of the environmental manager with other relevant understandings and knowledge systems (Díaz et al., 2015). The NCP concept recognizes the plurality of nature-related values, which is important when considering the range of impacts that conservation management actions might have on communities. Using this concept and the IUCN framework may enable decision-making that is more likely to both produce better outcomes for nature, enhance NCP, and avoid social conflict (Jacobs et al., 2020). However, NCP has not been used to date to explore conservation practice in urban settings, where it could be usefully applied to better understand enablers and constraints of engaging local communities in conservation actions.

Important to improving conservation practice is the acknowledgment that conservation science has traditionally stemmed from western ideas and concepts and as such is often limited in terms of engaging with the multiple definitions of and relationships people have with nature, especially Indigenous communities (Pascual et al., 2021). There is an ethical imperative to engage Indigenous peoples in land-use 
planning and environmental management in cities that have been developed on unceded Indigenous land, such as all cities in Australia and most cities on the American continent (Horton, 1996; Porter, 2018; Porter, Hurst, \& Grandinetti, 2020). This imperative is driven by an acknowledgement of Indigenous peoples' sovereignty but also of their custodianship and unique and deep knowledge of local environments (Mata et al., 2020). The IUCN framework, including NCP, is explicit in recognizing the contributions of Indigenous and local knowledge (Díaz et al., 2015). Generating a better understanding of the barriers and enablers to engaging Indigenous and non-Indigenous urban communities for biodiversity conservation will allow environmental managers to devise successful strategies for urban environmental stewardship (Briscoe \& Roberts, 2019; Threlfall et al., 2019).

This paper addresses the gap in understanding of how urban environmental managers across Australia engage local communities in conservation actions in the context of their role as facilitators of NCP. Our aims are to (1) explore how environmental managers engage communities, including Indigenous communities, in conservation actions, and (2) understand the factors that enable or constrain engagement with an aim to inform future community engagement and environmental management to enhance NCP.

\section{Materials and methods}

For this exploratory study, we chose a qualitative method that would enable a detailed understanding about the experiences of environmental managers and how they engaged communities in biodiversity conservation. All participation was voluntary, and participant and organizational data, including location, were de-identified for reporting.

\section{Study area and sampling}

Using purposive and snowball sampling, we sought to recruit environmental managers at organizations that have a role in urban biodiversity conservation. We targeted participants from state capital cities and their metropolitan regions across Australia to capture a diversity of projects and approaches across different states and urban settings. Interviews were conducted in Brisbane, Canberra, Melbourne, Perth, and Sydney. With exception of Canberra, which is Australia's largest inland city (with a population of more than 430,000 people), all other cities are coastal and have a population between 2 and 5 million people (ABS, 2021). Climate zones based on humidity and temperature vary between warm, humid summer (Brisbane), warm summer and cold winter (Melbourne, Perth, Sydney), to mild-warm summer and cold winter (Canberra) (BOM, 2016). All cities are located in the traditional lands of the Aboriginal groups that have lived and care for those regions for thousands of years (AIATSIS, 1996).

Participants were initially environmental managers from the researchers' networks where they worked in the study cities. The organizations targeted worked closely with communities for urban biodiversity conservation and included government (both state and local) and not-for-profit organizations. Each level of government works at a different scale, with state governments focusing on regional issues, and local or municipal governments limiting their focus to their local areas. Of the not-for-profit organizations in our research, all but one are registered charities. All participating not-for-profit organizations have a focus on environmental conservation and/or sustainability, often directed at specific geographic areas or regions (such as city or a part of a river) or issues (such as planting vegetation or collecting rubbish), and aim to benefit and engage broader society.

Sampling then snowballed to include urban environmental managers recommended by those initial participants. Sampling concluded once issues raised during interviews had been observed in prior interviews, meaning topics had reached saturation (Richards \& Morse, 2007).

\section{Instrument design}

This research is part of a broader investigation into urban actions for biodiversity conservation (Briscoe \& Roberts, 2019; Threlfall et al., 2019). Semi-structured interviews were chosen because they allow the flexibility to frame and follow-up responses in a conversational style and encourage information sharing, while also allowing for questions to be asked in a systematic manner (Bryman, 2012). The interview guide, comprising 13 questions, is available in Threlfall et al. (2019). The foci of this manuscript are the four questions concerning the factors that influence environmental managers' ability to both implement conservation actions and engage communities, the open-ended nature of the questions meant that interviews were wide-ranging.

\section{Data collection and analysis}

Three researchers (CER, KS, \& CGT) conducted the semistructured interviews over seven months between June 2018 and January 2019. Interviews took place at a location convenient to the participants, with the majority occurring at participants' place of work. Interviews varied in duration from 40 to $106 \mathrm{~min}$, with an average interview duration of $67 \mathrm{~min}$. All interviews were digitally recorded, and transcribed verbatim. Transcripts were imported into QSR NVivo 12 (QSR, 2012) for computer-assisted qualitative data analysis.

We used thematic content analysis to code the interviews into themes. Thematic content analysis is a common 
approach used to identify the elements of a participant's account (Green \& Thorogood, 2004). Iterative coding in NVivo was conducted first by the three interviewers who used constant comparison to ensure they were taking a similar coding approach. A fourth researcher (LT) performed additional sub-coding to categorize and further interpret only the coding pertaining to the community-engagement themes. Coding in this way allowed us to sort the data relevant to this part of the study into themes and sub-themes, and to group the topics into broader dimensions (Bryman, 2012). For example, the 'Indigenous engagement' dimension includes a theme about 'enablers' of actions and interactions. The 'enablers' theme includes sub-themes that group together policy enablers, comments that describe instances where internal reference groups have driven interactions or initiatives, and examples where individual interviewees described being driven by a concept of "doing the right thing".

\section{Findings}

We conducted 25 interviews with 27 participants (19 female) across the three organization types (Table 1). Interview reference codes are included in brackets after each quote. In two instances, two environmental managers from the same organization were interviewed simultaneously.
All interviewees described multiple biodiversity conservation actions undertaken by their organization. The aims described were to improve or provide habitat, control ecological threats, raise community awareness, provide environmental education, and build community capacity for environmental stewardship (Threlfall et al., 2019). This range of aims aligns with the objectives of NCP. Often a single described action addressed several aims simultaneously. For example, planting and weeding activities improved habitat and controlled ecological threats while also providing educational outcomes to participants.

We identified five key topics that interviewees reported as affecting conservation actions: 1) organizational differences influencing community engagement, 2) community as both a subject and enabler of projects; 3 ) managing complexity requiring resourcing and support; 4) varying engagement types; 5) values and connections being supportive of outcomes. For each of these topics, we identified the corresponding enablers and constraints or challenges discussed by participants (Fig. 1).

Participants from all organization types discussed issues relating to the five key topics we identified, as shown in Fig. 1. How organization types engaged communities (key topic 1) and the role of communities as subjects and enablers of projects (key topic 2) are both represented by the top row demonstrating whether participants discussed community engagement. Key topic 3 is represented by whether
Table. 1 Interviews in each city and corresponding set of reference codes by organization type.

\begin{tabular}{llllllll}
\hline & Ref & Brisbane & Canberra & Melbourne & Perth & Sydney & Total \\
\hline State Government & STA21-25 & 0 & 1 & 0 & 1 & 3 & 5 \\
Local Council & LOC08-20 & 0 & 0 & 5 & 4 & 4 & 13 \\
Not-For-Profit Organizations & NFP01-07 & 1 & 0 & 2 & 4 & 0 & 7 \\
Total & & 1 & 1 & 7 & 9 & 7 & 25 \\
\hline
\end{tabular}

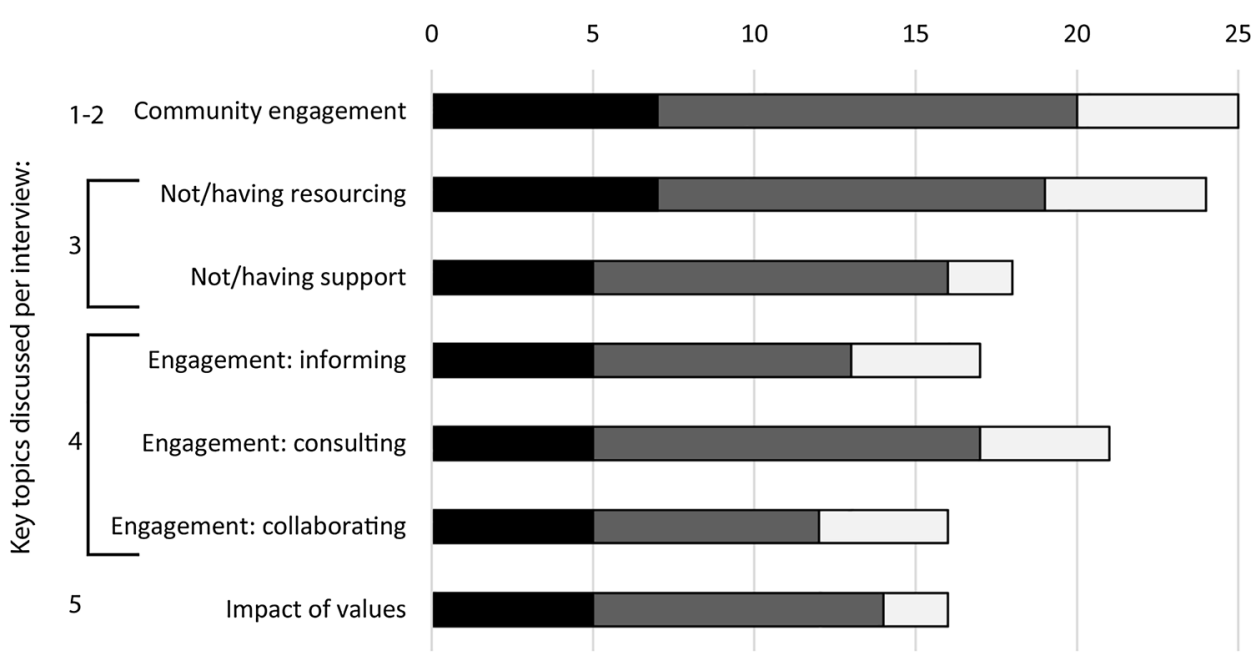

Fig. 1 Participants from all organization types discussed issues relevant to key topics during their interviews. If the key topics, listed on the left, were discussed in one of 25 interviews, the corresponding organization type is shown in the bars on the right. NFP refers to not-for-profit organizations, LOC refers to local governments, and STA refers to state governments, aligning with the interview reference codes noted in Table 1. 
participants discussed having or not-having resourcing and support. Key topic 4 is represented by participants discussing their engagement types: informing, consulting, collaborating. Key topic 5 is represented where participants discussed how values impact their work. For each key topic, we identified the corresponding enablers and constraints discussed by participants (Figure 2). Fig. 2 Key topics that affected conservation actions identified in the interviews are listed in the dark boxes on the left, corresponding enablers listed in the middle, and barriers or constraints are listed to the right.

\section{Organizational differences influence engagement}

As might be expected, the methods and degree to which urban environmental managers engaged local communities in conservation actions differed between organization types. The five state government employees we interviewed described limited engagement with communities compared to environmental managers from local governments $(n=13)$ or not-for-profit organizations $(n=7)$. For example, some interviewees from state governments indicated that their engagement with communities was limited: "we don't directly deal with the community" (STA23). Another state government interviewee noted they previously focused on a one-way justification for actions rather than consulting with communities: "our justification was: it's a restoration site and these are the restoration measures that we have to implement" (STA21). The same interviewee also acknowledged a shift in their organization's approach: "I think the community consultation thing is becoming much more important now... as the government starts pushing for more consultation". In contrast, interviewees from local councils described that "the community is ...key in terms of what could happen" (LOC16). Another local council interviewee noted that "one of our objectives is to engage with the community" (LOC08). Not-for-profit organizations, whose focus is on engaging with and acting for society, accepted close engagement with their communities as core to their work, clearly cognisant of NCP. For example, one interviewee noted "we get good community support" (NFP05). Another noted that "one of my biggest roles is volunteer coordination and management and development" (NFP03), demonstrating the focus on community volunteers.

The differences in how each organization type views the communities they serve affects how they engage with them. 'Top-down' influences, such as organizational policies and strategies, affect how the environmental managers we interviewed work. One local council interviewee explained that their mayor's preference for how the organization interacts with the community affected how they approached their work:
"We want community to tell us what they want... our mayor, he wants to be doing with or by the community rather than for the community. So, in trying to shift that, [we're] trying to build capacity within those people" (LOC11).

This 'top-down' approach highlights how an organization's values can support aspects of engagement. Another example of the 'top-down' approach demonstrates how a policy or strategy encourages engagement with key parts of a community, such as Indigenous Australians: "We've got [an] Aboriginal community liaison group [and] that helps because we've got a set group [that] is as representative as possible of all the different local [Indigenous] communities" (STA22).

\section{The community is both the subject and the enabler of conservation actions}

Most interviewees described the strong influence of community on actions to conserve urban biodiversity. Some environmental managers emphasized the ecological or conservation-focus of their role, for example: "we are very much focussed toward protecting and threat mitigation" (NFP04). However most interviewees framed their conservation actions around the communities they work with: "it's about human interaction, human interaction with that environment" (LOC17). People were seen as the targets of their conservation actions, but also as the enablers of conservation actions. One interviewee described their "close contact with people, and [ability to] drive some quite good changes in behaviour and education" (LOC12) as a result.

Despite interviewees' roles or job titles being environmentally or ecologically focused, key skills for environmental managers involved social interactions and influence. A state government interviewee described a newsletter intended "to give [the public] ecological information to influence how they saw the park" (STA24). A local council interviewee noted that their conservation actions aimed to "give the people ownership" (LOC13), emphasizing the importance of human-nature relationships and understanding NCP. Many environmental managers stressed that managing relationships was key to the success of projects. A local council interviewee noted that "everything relies on relationships for people to change or shift their view, they need to hear that information from a trusted person" (LOC19). It was clear that some environmental managers we interviewed worked with a range of stakeholders, managing multi-directional relationships that were critical in achieving biodiversity conservation and promoting NCP. A not-forprofit organization interviewee noted that "If you don't have partnerships with the landowners and local governments ... then you can't really do too much" (NFP03). 
Urban environmental managers stressed the importance of their organization's volunteer workforce and highlighted their efforts to engage volunteers. Volunteers were often relied on to achieve project outcomes, including planting, weeding, rubbish collection, monitoring of species or use of habitat boxes, and carrying out regular fauna surveys. One not-for-profit organization interviewee described their volunteer community, noting how fortunate they were to have "volunteers that consistently [participated]" (NFP01). Another not-for-profit organization interviewee said they have "consistent volunteers who come in every week and do specific tasks... [and] a lot of ad-hoc ones [volunteers] too who come in and out, and maybe only do one day a year" (NFP06). A local council interviewee raised a concern about their reliance on volunteers who are often older, noting that younger members of the community tend to show less interest in frequent volunteering:

"Organizations around land care really struggle and are going to struggle more now going into the future with things like volunteering. They won't be able to get the same amount of volunteers and their [current] volunteers are [in their] 80 s .... and they're not able to recruit new ones" (LOC12).

This point highlighted both the reliance on a volunteer workforce as well as the tenuous and inconsistent aspects associated with relying on such a resourcing strategy.

\section{Managing complexity: resourcing and support}

The need to integrate environmental management with community engagement demonstrated that interviewees' roles were complicated, and that they were aware of this. Discussions about the challenges that interviewees faced in their jobs suggested that relationships internal to their organizations were critical, though sometimes difficult. Several interviewees described having to spend time and resources trying to win internal support, including support for resource allocation and/or funding for projects. A local council interviewee shared a case where they failed to gain internal support for a project to trial one conservation action, but successfully attracted external support by way of funding. As a result of this external support the project was successful:

"we initially had a lot of resistance internally. People who were kind of a bit dismissive of doing those sorts of projects and they just thought it was a little bit of a big joke and a waste of money. So ...we got a built-in partnership with one of our coastal care groups... then we did camera-trap monitoring of the bridge, and it's being used every night by both species... [and] we got quite a lot of interest and engagement from the com- munity. So that's probably the [project] ...I'm most proud of" (LOC11).

One way of demonstrating internal support for engagement activities was through policies or organizational strategies. When such formal structures were absent, engagement relied on the commitment of the individual interviewees, producing variable results. This was evident with respect to engagement with Indigenous communities. For example, one local council interviewee noted, "I do genuinely have a deep respect for the culture, and I try to get that across... whenever I can" (LOC09). In some cases, interviewees highlighted a lack of commitment on the part of their organization in prioritizing Indigenous participation, particularly when costs were involved and resourcing was limited: "Consulting with Traditional Owners is really timeconsuming and can be expensive" (LOC15). Another example illustrated a practical way that organizations could ensure prioritizing Indigenous Australians' involvement:

"I think a lot of people think [Indigenous community contributions] should be free, but it is knowing the cost of that as well... If you wanted to pay an environmental consultant to tell you something you would happily pay them. But it is that understanding of payment [owed] to the Indigenous consultant and budgeting for that as well" (LOC20).

Where organizations had policies that reinforced the importance of Indigenous community engagement, these acted as internal mechanisms that meant interviewees did not have to struggle to gain this support. Indigenous reference or advisory groups dedicated to prioritizing and streamlining the involvement of Indigenous communities provided other means of support, such as one local council interviewee who explained that "the city has an Aboriginal reference group, who we can go to and raise and discuss things with, but also they drive a lot of the outcomes" (LOC12). This support and engagement also deepens understanding of the cultural dimensions of NCPs.

Interviewees from all three organization types identified political issues affecting their work. One local council interviewee admitted that "sometimes decisions are not based on data or recognised need. It might just be who's better known at the meeting. I think conservation is very far down the list" (LOC17). Another local council interviewee described having to campaign for the conservation actions they were proposing within the organization: "Our job... [is] to try and explain to them ... [why] we need to go in a particular direction" (LOC12). Repeated comments about the lack of support illustrated the difficult and complex political conditions many interviewees found themselves working in.

Even with political support, environmental managers faced financial constraints. Another local council 
interviewee said "The only way we can get around that [lack of] budget funding thing is trying to get residents involved and participating" (LOC10a). A not-for-profit organization interviewee described identifying a need for a project, but failing to secure the funding to support it:

"[I] must have been on about my fifth application for funding for a human-movement management plan... [the aim is to] guide people through [the area]... so that they can see and engage and the beauty of the place without, you know, damaging the natural values" (NFP05).

Regardless of organizational support, some interviewees explained that having to manage multiple stakeholders, including peers and contractors, made their roles more complex. For example, one local council interview-with two interviewees-described the environmental management part of their role as easy: "[It's] a simple, small revegetation job" (LOC18b). They added that community engagement can also work well: "It can be a real success ...[to] involve the local community ... [when] they've really taken ownership of it." However, having to influence their co-workers in other teams or contractors adds another layer of complexity, for example, the same interviewee described having to explain to maintenance staff that "You don't actually have to spray these areas all the time".

\section{Engagement types vary: informing, consulting, collaborating}

The interviewees described engagement types that we broadly categorized as informing, consulting, and collaborating. For example, a state-government interviewee expressed their role in informing the community: "[We] inform people of what we're doing and why we're doing it and what it's based on" (STA25). A not-for-profit organization interviewee suggested they had more of a two-way interaction consulting with the public: "We have done the community consultation [with]...local residents to get them on board" (NFP06). One local council interviewee (STA22) described their role in facilitating connections between private landowners and the local Indigenous community that enabled the use of traditional ecological practices (cultural burns) to maintain the landscape and allowing for greater custodianship of Country. Another example from a different local council explained that they work to empower the community because their organization aims to "get people to plant more trees in their own properties rather than a council being the one that's responsible for creating an urban canopy" (LOC11). A not-for-profit organization interviewee described a more collaborative approach: "We have a really good relationship with [a local] college... [and] because they knew us and they have a woodworking group, they provided 19 bat [roosting] boxes and the [local council]... installed them" (NFP03).

Key to ensuring both the effectiveness of community engagement and the longevity of conservation outcomes is environmental managers' ability to increase the reach of their programs so they include more people, including different demographic or cultural groups. However, when examples of scaling-up their projects were discussed, many interviewees described the work as challenging. One interviewee said that extending their project by "moving into a new demographic is... quite hard work" (LOC19). The same interviewee gave an example relating to a specific cultural group, saying they were "working with [the] Chinese community and other ethnic communities just to bring different groups in, but its hard work". The implication was that to reach a heterogenous community with different age groups and cultures takes a lot of effort, resources, and dedication. Another local council interviewee described the challenge of reaching diverse groups as typical to cities because it involves:

"that struggle of engaging youth, of engaging a very multicultural society, of engaging very busy time-poor families, of competing with all of the other life priorities that people have it's all of those typical issues ...[of] an urban community" (LOC09).

While most interviewees expressed the importance of engaging Indigenous Australian communities, the actual engagement varied. Simple approaches included inviting local Elders to welcome people to Country at the beginning of an event or, with permission, using Indigenous species and site names: "We use Aboriginal names in things that we do too and... if we have engagement with community we will always have an Acknowledgement of Country" (NFP05). Seeking endorsement from Indigenous groups to take environmental actions, or inviting members of local Indigenous groups to celebrate the outcomes of an environmental campaign are other examples of simple engagement types interviewees described that also draw out the cultural dimensions of NCP. Another interviewee described this 'bookend' approach: "[Indigenous groups are] involved at the start when we consult... [and] always at the end when we're... opening things or finishing up, they're part of that celebration" (LOC11). That initial approval can involve more detailed understanding and consultation, with a local council interviewee describing their process:

"We've got a policy that really encourages us to engage with Indigenous organizations, but on top of that, from an environmental perspective, we're doing that anyway, because we just understand there's that connec- 
tion from community and Country, and particularly for Indigenous Australians" (LOC12).

Examples of extensive engagement involved interviewees recognizing the rich cultural and ecological knowledge available through relationships with Indigenous peoples. For instance, some interviewees spoke of wanting to learn about the ecology of urban areas prior to European colonization. For example, one state government interviewee was keen to gain "a better understanding of how the land was utilized and managed... [to] inform some of the gaps in what the bushland looked like [in] pre-European [times]" (STA25). A local council interviewee said they contract cultural heritage management plans for an area prior to a new project, noting that "they're amazing, the information that's gathered. We really feel privileged to... understand a little bit more about ...that Country" (LOC18b). Again, this shows the value of using an NCP lens to explore and understand how environmental managers engage communities in biodiversity conservation. In addition to contracting Indigenous services for speaking events or cultural or ecological surveys, some interviewees gave examples of contracting Indigenous businesses for goods and services. Some organizations offered grants to support Indigenous-led programs in the community, and others were able to employ Indigenous people or utilize Indigenous-owned businesses. Some interviewees spoke of challenges trying to find local Indigenous people to be involved as “they're just busy because everyone wants to have ... some form of involvement [from local Indigenous people]" (LOC17). Despite the multiple examples of engagement, only a few involved co-design and/or co-creation, such as one state government interviewee who explained the collaborative model they used to engage their local Indigenous community:

"We've gone from the start in partnership, hand in hand, with the Aboriginal community [and] everything, from the naming of the site, to the way it's going be managed in the long term, to what they want to see planted there in terms of bush tucker... it's all got to be delivered together. You know ...that's, I think, really the way forward" (STA21).

\section{Values and connection support outcomes}

Interviewees used at least three types of engagement to understand how communities valued nature: capitalizing on existing values and connection with nature; inspiring new, positive values and connections with nature; and reducing conflict. The first type of engagement capitalized on the existing values and connection that people had with their local nature, aligning with the concept of relational values. Interviewees described examples where it was easier to gain support for conservation actions because people already valued the subject of the work. For example, one interviewee noted that the conservation work focused on bandicoots, an Australian marsupial, was easier because "the reaction of the residents... [it] really promoted a sense of positive ownership ...just to see those creatures up close, it is super aweinspiring for people" (LOC14). Another interviewee said their not-for-profit organization gets "huge amounts of community participation because [the particular land we work on is] not a patch of a scrub out the back of nowhere ... people love it" (NFP04). By capitalizing on aspects of nature that the community values and already has a clear relationship with (in this example, an area of the river), interviewees suggested they can achieve more than they otherwise might without community support. Another not-for-profit organization interviewee described a campaign focussed on the powerful owl (Ninox strenua), noting that because of the connection with this animal from the local community "the reaction that we get from people, and it's the level of engagement... because people ...really want to be involved, like they really want to do something" (NFP02). Building on aspects where communities already hold relational values with nature is one way to ensure low-risk engagement and potentially influence the success of conservation actions, while also demonstrating NCP.

The second type of engagement occurred when people held few positive values about nature and environmental managers aimed to inspire this sense of connection to achieve conservation outcomes. A local council interviewee stressed that "If you don't have a connection with it, you don't care about it, and it's never going to be protected, so I'm all about getting people [involved]" (LOC17). For example, another local council interviewee described a campaign to raise awareness about and inspire connection with bandicoots:

"That's the whole plan [to] get people more passionate about it ...like the bandicoots ...people are going, 'I had no idea. I thought they were a big rat.' I suppose we had to stop taking for granted that everybody knew what we thought they should know" (LOC11).

The third type of engagement involved reducing conflict by employing integrated designs and encouraging mixed land uses in urban areas. Rather than advocating for land sparing and protection alone, the emphasis was on making land/environmental management and design decisions that acknowledged a variety of uses in certain areas, to reflect broader aspects of NCP. A local council interviewee noted that "a mixture of spaces is required in this situation... particularly [to accommodate] things like dogs. Dogs off leash... can have massive impacts on biodiversity" (LOC17). The challenge of being able to provide people with access to nature to accommodate various uses and types of engagement while conserving biodiversity is often the 
aim of environmental management in cities. A not-for-profit organization interviewee described an example about conserving a local samphire plant:

"We didn't want them trampling the samphire ...so we raised funds to build a very quiet, low-impact little viewing platform allowing access to the natural values of the river, without destroying them... it was a simple change [and made a] massive change to the survival rate of the species out there, and humans are still happy. I have great faith in the capacity of natural values of the river and other urban bushland areas to be protected and be conserved and enjoyed" (NFP05).

Another example involved a new urban development, and the interviewee described their passion about integrating biodiversity: "I want to make a biodiversity friendly development... We need to help people, I think, if we're going to achieve that" (NFP07). A state government interviewee explained that they survey the community to find out how they like to use public parklands. The aim is to understand existing relationships and inform how public parks are upgraded or maintained. They described the survey questions as: "Why do you use the park? How do you use the park? What do you want to improve or change?" (STA24). Active engagement with the public to inform environmental works in this way demonstrates a socioecological approach to managing urban nature with values and conflict-mitigation in mind. In line with the cultural aspects of NCP, engagement with local Indigenous peoples offers the opportunity to extend the approach to include the ecocultural, for example a local council interviewee described the outcomes from engaging an Indigenous Elder:

"He was telling ...stories about his life along the river as a child and ...he mentioned that it would be really

\begin{tabular}{|c|c|c|}
\hline Key areas & Enablers & Barriers/constraints \\
\hline $\begin{array}{c}\text { Organizational } \\
\text { differences influence } \\
\text { engagement } \\
\text { (State \& local government, NFP) }\end{array}$ & $\begin{array}{c}\text { Supportive polices \& } \\
\text { strategies }\end{array}$ & $\begin{array}{l}\text { Lack of top-down } \\
\text { commitment }\end{array}$ \\
\hline $\begin{array}{l}\text { Community is both } \\
\text { subject } \mathbb{\&} \text { enabler of }\end{array}$ & $\begin{array}{c}\text { Influence \& engagement } \\
\text { with community }\end{array}$ & $\begin{array}{l}\text { Aging volunteers; young } \\
\text { people uninvolved }\end{array}$ \\
\hline $\begin{array}{c}\text { actions } \\
\text { (Relationships drive projects) }\end{array}$ & Volunteer workforce & Lack of internal support, \\
\hline $\begin{array}{l}\text { Managing complexity: } \\
\text { resourcing and support } \\
\text { (External \& internal influence } \\
\text { needed) }\end{array}$ & $\begin{array}{l}\text { Indigenous advisory or } \\
\text { reference groups }\end{array}$ & $\begin{array}{l}\text { - } \quad \text { Approval for projects } \\
\text { - } \quad \text { Financial resources } \\
\text { - } \quad \text { Colleagues \& } \\
\text { contractors }\end{array}$ \\
\hline Engagement types vary & $\begin{array}{c}\text { Different levels of } \\
\text { engagement }\end{array}$ & $\begin{array}{l}\text { Reliance on individuals } \\
\text { (vs. building systemic support) }\end{array}$ \\
\hline $\begin{array}{l}\text { (Informing, consulting, } \\
\text { collaborating) }\end{array}$ & $\begin{array}{l}\text { Scaling up via cultural \& } \\
\text { generational groups }\end{array}$ & $\begin{array}{l}\text { Reliance on simple } \\
\text { engagement types }\end{array}$ \\
\hline $\begin{array}{l}\text { Values and connection } \\
\text { support outcomes } \\
\text { (Existing or inspire value, adapt } \\
\text { via design) }\end{array}$ & $\begin{array}{c}\text { Human-nature integrative } \\
\text { design }\end{array}$ & $\begin{array}{c}\text { Awareness-raising } \\
\text { needed }\end{array}$ \\
\hline
\end{tabular}

Fig. 2 Key areas that affected conservation actions identified in the interviews are listed in the dark boxes on the left, corresponding enablers listed in the middle, and barriers or constraints lis to the right. 
nice... to have that documented somehow... [We] got interpretive signs that told a story and... [now there are] eight or nine signs and trails have been renamed there" (LOC11).

These three engagement types demonstrate how environmental managers consider pluralistic values-or a range of social, cultural and ecological values-when engaging communities.

\section{Example case study: pluralistic values at work in a not-for-profit organization's initiative}

Here, we provide a case study that describes one of the interviewee's (NFP05) organization's approach, their conservation work, and the feedback received from the public. This example demonstrates the facilitation of NCP and blending of value types in environmental management. Figure 3 distils the aims of the organization when it comes to addressing the key pluralistic values and aligns it with a quote from the interviewee.

The not-for-profit organization aims to support its local community by organizing biodiversity conservation works to restore designated conservation sites. It has 40-50 active members who paid a small fee for their membership. In addition, they have hundreds of volunteers who join their activities because, according to the interviewee, local residents care about protecting the area and want to be "part of the solution". Indigenous groups occasionally send teams of young people to them to help them do the work, and the organization invites local Indigenous Elders to share cultural knowledge about appropriate sites. Companies partner with the organization and send their staff to participate in works

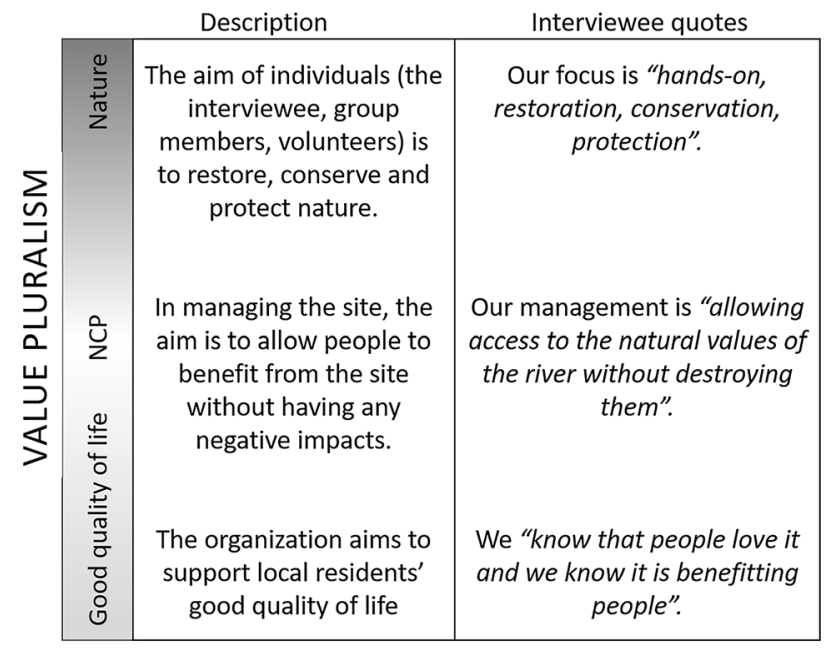

Fig. 3 This case study illustrates how diverse values are integrated in successful environmental-management programs. on team building days as volunteers. Unless the organization is successful in securing grants to fund contractors and major works, they are limited to organizing volunteer work, such as planting and weeding by hand.

The site is on a public nature reserve by an iconic river within a residential area. It was initially overrun with invasive weeds that overran the underlying native plants. The organization and volunteers removed the weedy species in line with a management plan for the site and the riparian vegetation underneath began to recuperate. Aware of the ecological and cultural importance of the site, all work was done with care. To manage human use of the site, they built a low fence along a path to protect the restored vegetated area and animal species that use it as habitat. They raised funding to build a viewing platform and seating so all members of the public, including those in wheelchairs, could enjoy the area without impacting the vegetation. Maintenance of the site is ongoing.

The feedback mechanisms for the conservation action were both formal and informal. For example, when members of the group are present doing maintenance work, the public made informal comments to thank them and tells them, "It's looking good" when they walk by. One formal feedback mechanism included a recent ecological assessment that declared the site in "very good" condition. A bird species that was locally extinct was seen after the restoration work commenced. The interviewee described works at this site as being one of the projects of which they were most proud.

The enablers for this case study, as shown in Fig. 2, include the organization's engagement with the community and the community support they receive via active membership and voluntary work. The volunteer workforce is a significant enabler, though one of the challenges is that many of the volunteers and members are older ("a lot of us are pretty grey-haired now"), without sufficient candidates for succession. The integrated human-nature design employed by the organization is an enabler that feeds into the success of the conservation work. The lack of financial resources is a constraint, with the not-for-profit organization applying for grants to fund activities beyond the work the volunteers contribute.

\section{Discussion}

\section{Overview}

Our research provides an understanding of how environmental managers in Australian cities engage communities and how this can be understood using the lens of NCP. Interviewees described different types of community engagement that recognized a range of values, or value pluralism, (Martin et al., 2016a) in urban communities. 
Environmental managers adjusted their engagement based on the broad relational values that people held toward nature, such as whether people already felt a strong sense of connection to nature, or whether some encouragement and engagement work was required. The key enablers and constraints that environmental managers faced could be categorised based on whether the relationship was internal to their organization, or with external community. Constraints, such as a lack of top-down commitment or simplistic engagement strategies, consistently aligned with value monism. In contrast, enablers such as supportive organization policies and multi-use integrative human-nature designs typified value pluralism (Fig. 4). Ultimately, approaches that aligned with value pluralism facilitated effective conservation action in urban environments, while approaches driven by value monism were barriers.

\section{Value pluralism enables conservation actions}

In cities, where there are multiple stakeholder organizations, diverse values and roles, an approach that embraces value pluralism of human-nature relationships is an enabler for engagement. Despite the focus of our interviewees' work being biodiversity conservation, engagement was viewed as critical in achieving those outcomes (Backstrom et al., 2018; Endter-Wada et al., 1998; Ives \& Kendal, 2014). Community-driven conservation actions often had social outcomes as well. Environmental managers described connecting with community members in different roles, such as engaging with volunteers in notfor-profit organizations (i.e., willing actors in conservation actions). They also interacted with residents and landowners (i.e., targeted potential actors due to their capacity to contribute to conservation via their assets) and the public generally, adjusting their engagement approach to suit the community's perspectives and values of nature. This shows that first, environmental managers recognized different perspectives and values (Martin et al., 2016b), and second, that in responding accordingly, engaging people for conservation outcomes was more likely to be successful while also enabling NCP. Including multiple knowledge systems and cultures in a program of work is critical for successful engagement in a culturally diverse country like Australia (A. B. o. S. ABS, 2017). As such, we suggest that value pluralism is an enabler of conservation work in cities, where people are impacted by conservation actions (Young et al., 2010).

\section{Organizational support for engagement is critical to conservation action}

The capacity of urban environmental managers to engage the community and undertake biodiversity conservation actions depends largely on the support provided by their organization. An organizational strategy can signal 'top down' support for certain types of engagement, such as dedicated resourcing for Indigenous engagement initiatives or a commitment to public consultation. Similarly, organizational strategies that encourage inclusiveness have the potential to mitigate power differences and dynamics. The shift from a focus of top-down to more inclusive approaches in environmental management was evident in our research and reflects a global trend (Armitage et al., 2012). Conversely, the lack of a clear organizational strategy or preference for a type of engagement leaves space for variable actions and power struggles. For example, our interviewees frequently spoke of having to campaign for support for biodiversity conservation from within their organization.

Shifts in power often occur when there are socio-ecological trade-offs, requiring one stakeholder to be the 'winner' and another to be the 'loser' (Ellis et al., 2019). The potential to ignore or downplay a stakeholder's relationship
Fig. 4 A summary of the approaches, organizational mechanisms and engagement styles grouped into enablers (hollow shapes) and constraints (shaded shapes) based on interviews with environmental managers in Australian cities.

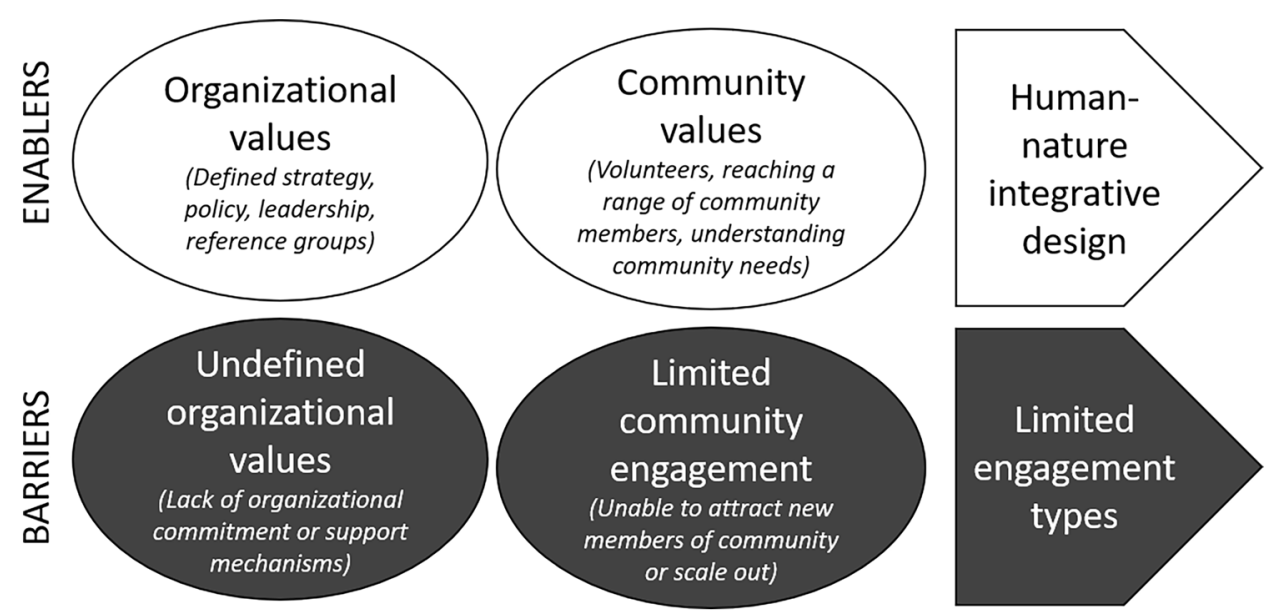


with nature demonstrates the extent that power and values determine the management decisions of a landscape (Ellis et al., 2019). In Australia, there are important nature-related values relating to conservation that might be detrimentally downplayed by an organization's power dynamics. Examples include: Indigenous connections to Country, a volunteer's connection to a river, or simplifying urban residents' quality of life (given that quality of life is multidimensional, see Stone \& Mackie, 2013). Lack of a clear organizational preference or support for broad engagement therefore becomes a constraint for environmental managers (Fig. 4). Organizations can emphasize their support for broad engagement via a strategy (such as providing all staff with cultural competence training), policies (such as prioritizing engagement), or sub-structures (such as advisory groups).

\section{Consistent enthusiasm for Indigenous involvement, but inconsistent engagement}

Aligning with the cultural dimension of NCP, our research revealed that environmental managers were consistent in their desire to engage Indigenous Australians in conservation actions. Importantly, Indigenous community engagement was strongest when interviewees' actions were supported by 'top down' organizational mechanisms, and a lack thereof acted as a constraint (Fig. 4). For example, organizational mechanisms that can support engagement include the presence of an Indigenous advisory group, and a policy to guide Indigenous engagement prior to project commencement. This 'top down' approach guides and supports engagement with local Indigenous communities and individuals, also making sure that those are not overburden by multiple requests within the same organization.

However, despite the enthusiasm for Indigenous engagement, the co-creation or co-design of conservation actions with Indigenous communities and interviewee groups was rare. Co-design of projects or actions is collaborative and enables emphasis to be shared between groups (Dreise \& Mazurski, 2018). It requires groups to participate throughout the project, including planning and leadership, and includes a dual lens for learning and decision-making (Dreise \& Mazurski, 2018). Co-design affords a pluralistic approach to ontologies as well as values (Parsons et al., 2016), as illustrated by Fig. 4. The scarcity of examples of projects where co-design was used, means that there is a still a long journey ahead in this space of working alongside First Nations people in biodiversity conservation and natural resource management in Australian cities.

\section{A range of engagement types produces strong community engagement}

Engaging communities in urban conservation actions can take a range of forms. For example, the International Association for Public Participation Australasia describes a spectrum ranging from the simpler activities of informing and consulting, to more complex engagement such as involving, collaborating and empowering (International Association for Public Participation Australasia, 2014). Relying only on the simple end of the spectrum fails to both acknowledge different values and engage different perspectives, potentially restricting community engagement in urban biodiversity conservation. For example, an environmental manager may say that the public needs education to understand the need for a particular conservation action, but conflict may originate from differences in underlying values rather than knowledge (Hull et al., 2003). Alternatively, a conservation project may not proceed due to a lack of resources or a lack of organizational support to conduct sufficient engagement with the community. Limited engagement is therefore a constraint for urban conservation action.

Conversely, we found that when environmental managers had the time, support, and funds to utilize multiple forms of involvement, the result was strong engagement: engagement then becomes an enabler of conservation action (Fig. 4). An example of a multi-stage engagement program could include an initial campaign to provide information, followed by workshops and consultation, with the option to co-create a management plan (for examples, see: City of Melbourne, 2017; Mairie de Paris, 2018). Multiple and responsive engagement methods can reach more people (including different demographics and cultures) and provide the foundation for long-lasting relationships. Throughout our interviews, we noticed a shift away from a reliance on the informing end of engagement in favor of more collaboration and co-creation. However, it must be recognized that these forms of engagement are resource-intensive and organizations can streamline engagement by implementing the top-down processes and policies discussed earlier.

A common form of engagement, both within Australia and around the world, is the involvement of volunteers in conservation actions (Measham \& Barnett, 2008). In our study, volunteers were often key to implementing conservation actions in Australian cities. However, if volunteer recruitment cannot be sustained, it presents a potential risk to an organization's ability to manage environments over time (Measham \& Barnett, 2008). For example, environmental managers in our study described difficulties in attracting new members from younger generations. There are many reasons why people would volunteer to support conservation actions that environmental managers might draw on to promote recruitment. For instance, conservation volunteers are motivated to participate through many aspects of NCP, e.g. to support their physical health, their mental health 
and community wellbeing, or to socially engage with others and enjoy nature (Takase et al., 2019). By focusing on volunteers' motivations and supporting them via programs designed to kindle and sustain their enthusiasm, organizations can compensate/give back to their volunteers (albeit not via financial means) and ensure that the volunteer workforce will be renewed over time (Takase et al., 2019).

\section{Conclusion}

Environmental managers need to engage with, and gain the support of, local communities to achieve positive biodiversity outcomes in cites. This is a complex task that they currently do with little guidance. Nature's contribution to people (NCP), which represents the complex relationships between nature and human wellbeing, is a fitting lens for exploring how environmental managers engage communities in biodiversity conservation. This is particularly the case in cities, which are complex socio-ecological environments that comprise a layering of heterogenous, novel landscapes, changing ecosystem function, culturally diverse human communities, and a range of institutions and power dynamics. We found a range of enablers and challenges useful for informing future environmental management and community engagement. Above all, despite their focus on biodiversity conservation actions, the environmental managers we interviewed described the importance of social interactions in their work, demonstrating their crucial position at the nexus of nature and people as facilitators of NCP. Exploring how environmental managers consider both 'humans' and 'nature', or the 'more-than-human', aspects of cities in conservation actions will increase the likelihood of improved outcomes for urban socio-ecological systems.

Acknowledgements The University of Melbourne Faculty of Science Human Ethics Advisory Group granted approval to conduct this research (approval number 1851835.1).

We acknowledge the Traditional Owners of the unceded Country on which this project was undertaken, including the Dharug, Wiradjuri, Tharawal and Wangal of the Eora Nation (Sydney), the Turrbal and Yugara (Brisbane), the Whadjuk and Pinjarup of the Noongar Nation (Perth), the Ngunnawal (Canberra) and the Boonwurrung and Wurundjeri Woi Wurrung of the Kulin Nation (Melbourne).

We thank the interviewees for participating in this research and sharing their time, insights and experiences. We thank INDIGI LAB and Luke Briscoe for their report (Briscoe \& Roberts, 2019) that informed this project, in addition to useful discussions with Professor Dieter Hochuli. This research was supported by the Australian Government's National Environmental Science Program through the Clean Air and Urban Landscapes Hub and the Threatened Species Recovery Hub. LT was supported by a University of Melbourne Faculty of Science grant awarded to CGT. CGT is also supported by an Australian Research Council Discovery Early Career Researcher Fellowship (DE200101226). AA was supported by a Denison student scholarship awarded by The University of Sydney.
Open Access This article is licensed under a Creative Commons Attribution 4.0 International License, which permits use, sharing, adaptation, distribution and reproduction in any medium or format, as long as you give appropriate credit to the original author(s) and the source, provide a link to the Creative Commons licence, and indicate if changes were made. The images or other third party material in this article are included in the article's Creative Commons licence, unless indicated otherwise in a credit line to the material. If material is not included in the article's Creative Commons licence and your intended use is not permitted by statutory regulation or exceeds the permitted use, you will need to obtain permission directly from the copyright holder. To view a copy of this licence, visit http://creativecommons.org/licenses/by/4.0/.

\section{References}

ABS. (2021, 30/03/2021). Regional population. Retrieved from https:// www.abs.gov.au/statistics/people/population/regional-population/ latest-release

ABS, A. B. o. S. (2017). Census reveals a fast changing, culturally diverse nation. Retrieved from https://www.abs.gov.au/ausstats/ abs\%40.nsf/lookup/Media\%20Release3

AIATSIS, A. I. o. A. a. T. S. I. S. (1996). Map of Indigenous Australia. Retrieved from https://aiatsis.gov.au/explore/map-indig enous-australia

Armitage D, de Loë R, Plummer R (2012) Environmental governance and its implications for conservation practice: Environmental governance. Conserv Lett 5(4):245-255. https://doi.org/10.1111/j. 1755-263X.2012.00238.X

Backstrom AC, Garrard GE, Hobbs RJ, Bekessy SA (2018) Grappling with the social dimensions of novel ecosystems. Front Ecol Environ 16(2):109-117. https://doi.org/10.1002/fee.1769

Barraket, J. (2004). Communities of place. Griffith REVIEW(3), 184-189.

BOM, B. o. M. (2016). Climate classification of Australia (temperature/humidity zones). Retrieved from http://www.bom.gov. $\mathrm{au} / \mathrm{jsp} / \mathrm{ncc} / \mathrm{climate}$ averages/climate-classifications/index.jsp? maptype $=$ kpngrp\#maps

Briscoe, L., \& Roberts, A. (2019). Indigenous Engagement: Report on actions for biodiversity. Retrieved from https://nespurban. edu.au/wp-content/uploads/2019/06/Actions-for-BiodiversityPART-II.pdf

Bryman A (2012) Social research methods, Fourth edition. Oxford University Press, Oxford

Buijs AE, Mattijssen TJ, Van Der Jagt AP, Ambrose-Oji B, Andersson E, Elands BHM, Steen Møller M (2016) Active citizenship for urban green infrastructure: fostering the diversity and dynamics of citizen contributions through mosaic governance. Curr Opin Environ Sustain 22:1-6. https://doi.org/10.1016/j. cosust.2017.01.002

Carlsson L, Berkes F (2005) Co-management: concepts and methodological implications. J Environ Manage 75(1):65-76. https:// doi.org/10.1016/j.jenvman.2004.11.008

Chan KMA, Balvanera P, Benessaiah K, Chapman M, Diaz S, Gomez-Baggethun E, Turner N (2016) Why protect nature? Rethinking values and the environment. Proc Natl Acad Sci USA 113(6):1462-1465. https://doi.org/10.1073/pnas.15250 02113

Chan KMA, Gould RK, Pascual U (2018) Editorial overview: Relational values: what are they, and what's the fuss about? Curr Opin Environ Sustain 35:A1-A7. https://doi.org/10.1016/j.cosust.2018. 11.003 
City of Melbourne. (2017). Nature in the city: Thriving biodiversity and health ecosystems. Retrieved from melbourne.vic.gov.au/ urbannature

Díaz S, Demissew S, Carabias J, Joly C, Lonsdale M, Ash N, Stockholm Resilience C (2015) The IPBES Conceptual Framework - connecting nature and people. Curr Opin Environ Sustain 14:1-16. https://doi.org/10.1016/j.cosust.2014.11.002

Dreise, T. and Mazruski, E., 2018. Weaving knowledges: knowledge exchange, co-design and community-based participatory research and evaluation in Aboriginal communities. Aboriginal Affairs New South Wales, editor.

Ellis EC, Pascual U, Mertz O (2019) Ecosystem services and nature's contribution to people: negotiating diverse values and trade-offs in land systems. Curr Opin Environ Sustain 38:86-94. https://doi. org/10.1016/j.cosust.2019.05.001

Endter-Wada J, Blahna D, Krannich R, Brunson M (1998) A framework for understanding social science contributions to ecosystem management. Ecol Appl 8(3):891-904. https://doi.org/10.1890/ 1051-0761(1998)008[0891:AFFUSS]2.0.CO;2

Green J, Thorogood N (2004) Qualitative methods for health research. SAGE Publications Ltd, Los Angeles, California

Horton, D. R. (1996). AIATSIS map of Indigenous Australia. Retrieved from https://aiatsis.gov.au/explore/articles/aiatsis-map-indig enous-australia

Hull RB, Richert D, Seekamp E, Robertson D, Buhyoff GJ (2003) Understandings of environmental quality: ambiguities and values held by environmental professionals. Environ Manage 31(1):1-13. https://doi.org/10.1007/s00267-002-2812-6

International Association for Public Participation (IAP2) Australasia. (2014). Public participation spectrum. Retrieved from https://iap2. org.au/resources/spectrum/

International Union for Conservation of Nature. (1996). Resolutions and recommendations. Paper presented at the World Conservation Congress, Montreal (Canada).

Ives CD, Kendal D (2014) The role of social values in the management of ecological systems. J Environ Manage 144:67-72

Ives CD, Lentini PE, Threlfall CG, Ikin K, Shanahan DF, Garrard GE, Kendal D (2016) Cities are hotspots for threatened species. Glob Ecol Biogeogr 25(1):117-126. https://doi.org/10.1111/geb.12404

Jacobs S, Zafra-Calvo N, Gonzalez-Jimenez D, Guibrunet J, Benessaiah K, Berghöfer A, Balvanera P (2020) Use your power for good: plural valuation of nature - the Oaxaca statement. Global Sustain 3(e8):1-7. https://doi.org/10.1017/sus.2020.2

Kendal D, Ford RM (2018) The role of social license in conservation. Conserv Biol 32(2):493-495. https://doi.org/10.1111/cobi.12994

Mairie de Paris. (2018). Paris Resilience Strategy. Retrieved from www.paris.fr/municipalite/action-municipale/paris-resil iente-4264

Maller C (2018) Healthy urban environments : more-than-human theories. Abingdon, Oxon, Routledge

Martin A, Coolsaet B, Corbera E, Dawson NM, Fraser JA, Lehmann I, Rodriguez I (2016a) Justice and conservation: The need to incorporate recognition. Biol Cons 197:254-261. https://doi.org/10. 1016/j.biocon.2016.03.021

Martin A, Coolsaet B, Corbera E, Dawson NM, Fraser JA, Lehmann I, Rodriguez I (2016b) Justice and conservation: The need to incorporate recognition. Biol Conserv 197:254-261. https://doi.org/10. 1016/j.biocon.2016.03.021
Mata L, Ramalho CE, Kennedy J, Parris KM, Valentine L, Miller M, Cumpston Z (2020) Bringing nature back into cities. People Nature. https://doi.org/10.1002/pan3.10088

Measham TG, Barnett GB (2008) Environmental Volunteering: motivations, modes and outcomes. Aust Geogr 39(4):537-552. https:// doi.org/10.1080/00049180802419237

Parsons M, Fisher K, Nalau J (2016) Alternative approaches to codesign: insights from indigenous/academic research collaborations. Curr Opin Environ Sustain 2016(20):99-105

Pascual U, Balvanera P, Díaz S, Pataki G, Roth E, Stenseke M, Lunds U (2017) Valuing nature's contributions to people : the IPBES approach. Curr Opin Environ Sustain 26-27:7

Pascual U, Adams WM, Díaz S, Lele S, Mace GM, Turnhout E (2021) Biodiversity and the challenge of pluralism. Nat Sustain. https:// doi.org/10.1038/s41893-021-00694-7

Porter L (2018) From an urban country to urban Country: confronting the cult of denial in Australian cities. Aust Geogr 49(2):239. https://doi.org/10.1080/00049182.2018.1456301

Porter L, Hurst J, Grandinetti T (2020) The politics of greening unceded lands in the settler city. Aust Geogr. https://doi.org/10. 1080/00049182.2020.1740388

QSR. (2012). NVivo qualitative data analysis software (Vol. 12): QSR International Pty Ltd.

Redpath SM, Bhatia S, Young J (2015) Tilting at wildlife: reconsidering human-wildlife conflict. Oryx 49(2):222-225. https://doi.org/ $10.1017 / \mathrm{S} 0030605314000799$

Richards L, Morse JM (2007) Readme first for a user's guide to qualitative methods, 2nd edn. Sage Publications, Thousand Oaks Calif

Shaffer HB (2018) Urban Biodiversity Arks. Nature Sustainability 1(12):725-727. https://doi.org/10.1038/s41893-018-0193-y

Soanes K, Lentini PE (2019) When cities are the last chance for saving species. Front Ecol Environ 7(4):225-231. https://doi.org/10. 1002/fee.2032

Stone AA, Mackie C (2013) Subjective well-being: measuring happiness, suffering, and other dimensions of experience. National Academies Press, Washington DC

Takase Y, Hadi A, Furuya K (2019) The relationship between volunteer motivations and variation in frequency of participation in conservation activities. Environ Manage 63(1):32-45. https://doi.org/10. 1007/s00267-018-1106-6

Threlfall, C. G., Soanes, K., Ramalho, C. E., Aiyer, A., Parris, K., \& Maller, C. (2019). Conservation of urban biodiversity: a national summary of local actions. Retrieved from https://nespurban.edu. au/wp-content/uploads/2019/06/Actions-for-Biodiversity-PARTII.pdf

Whatmore S (2006) Materialist returns: practising cultural geography in and for a more-than-human world. Cult Geogr 13(4):600-609. https://doi.org/10.1191/1474474006cgj377oa

Young J, Marzano M, White R, McCracken D, Redpath S, Carss D, Watt A (2010) The emergence of biodiversity conflicts from biodiversity impacts: characteristics and management strategies. Biodivers Conserv 19(14):3973-3990. https://doi.org/10.1007/ s10531-010-9941-7

Publisher's Note Springer Nature remains neutral with regard to jurisdictional claims in published maps and institutional affiliations. 